\title{
Post-meeting Curation of Whiteboard Content Captured with Mobile Devices
}

\author{
Danniel Varona-Marin ${ }^{1}$, Jan A. Oberholzer ${ }^{2}$, Edward Tse ${ }^{3}$, Stacey D. Scott ${ }^{1,2}$ \\ ${ }^{1}$ Systems Design Engineering \\ ${ }^{2}$ School of Computer Science \\ ${ }^{3}$ NUITEQ \\ University of Waterloo Water- \\ University of Guelph \\ loo, ON, Canada \\ Guelph, ON, Canada \\ Calgary, AB, Canada \\ danniel.vm@gmail.com \\ \{roberhol|stacey.scott\}@ uoguelph.ca \\ et@nuiteq.com
}

\begin{abstract}
The traditional dry-erase whiteboard is a ubiquitous tool in the workplace, particularly in collaborative meeting spaces. Recent studies show that meeting participants commonly capture whiteboard content using integrated cameras on mobile devices such as smartphones or tablets. Yet, little is known about how people curate or use such whiteboard photographs after meetings, or how their curation practices relate to post-meeting actions. To better understand these postmeeting activities, we conducted a qualitative, interviewbased study of 19 frequent whiteboard users to probe their post-meeting practices with whiteboard photos. The study identified a set of unmet design needs for the development of improved mobile-centric whiteboard capture systems. Design implications stemming from the study include the need for mobile devices to quickly capture and effortlessly transfer whiteboard photos to productivity-oriented devices and to shared-access tools, and the need to better support the extraction of whiteboard content directly into other productivity application tools.
\end{abstract}

\section{Author Keywords}

whiteboard photos; whiteboard content; curation; mobile devices; collaboration; whiteboard photo lifecycle.

\section{ACM Classification Keywords}

H.5.m. Information interfaces and presentation (e.g., HCI):

\section{INTRODUCTION}

Research on whiteboard use to aid in the development of whiteboarding systems has been a staple in the field of $\mathrm{Hu}-$ man-Computer Interaction (HCI), particularly in the Computer Supported Collaborative Work (CSCW) literature. Since early seminal work at Xerox PARC [9, 33, 39, 42],

Permission to make digital or hard copies of all or part of this work for personal or classroom use is granted without fee provided that copies are not made or distributed for profit or commercial advantage and that copies bear this notice and the full citation on the first page. Copyrights for components of this work owned by others than ACM must be honored. Abstracting with credit is permitted. To copy otherwise, or republish, to post on servers or to redistribute to lists, requires prior specific permission and/or a fee. Request permissions from Permissions@acm.org.

ISS '18, November 25-28, 2018, Tokyo, Japan (c) 2018 Association for Computing Machinery. ACM ISBN 978-1-4503-5694-7/18/11 ..\$15.00 much of the research has concentrated on supporting remote collaboration $[8,10,50,51]$, sketch recognition $[19,20,22]$, and integration of whiteboards with other meeting tools and systems [2, 11, 29, 41]. Most of these studies, however, investigated how to support whiteboard use during meetings, yet little is known about how to support post-meeting use of whiteboard content.

Moreover, despite the long history of research on whiteboarding systems, and the commercial availability of many interactive whiteboarding systems (including systems offered by the company of some of the authors), traditional dryerase whiteboards are still ubiquitous in many offices and collaborative meetings spaces, and are often the tool of choice during collaborative meetings. A recent study by Klokmose \& Bertelsen [16] found that meeting participants often use mobile phones to capture whiteboard content during or at the end of a meeting (Figure 1).

However, little is known about how people use such whiteboard content after a meeting. Are whiteboard photos handled like personal photos? Does existing research on personal photo curation (e.g., [49]), and do related photo curation technologies apply to this type of virtual content? This dearth of knowledge makes it difficult to develop effective collaboration tools that address post-meeting needs. To address this research gap, we conducted a study of people's whiteboard content curation processes and practices. Our overarching research question was: What do people do with whiteboard photos after a meeting? To answer this question, we conducted a series of semi-structured interviews with 19 participants who regularly used whiteboards. They were recruited from various professions, companies, and industries across North America.

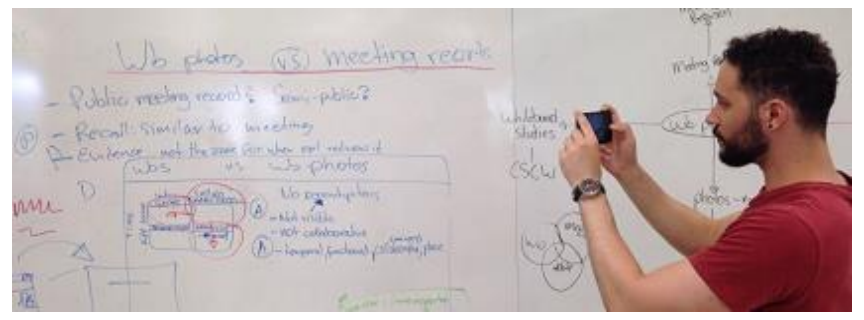

Figure 1. A meeting attendee using a smartphone to capture whiteboard content generated during a group meeting 
The study found that whiteboard photos are often used as a meeting record because people fail to recall finer details of whiteboard content from meetings. Whiteboard photos are also managed and valued differently than personal photos, and tend to have more fleeting value that is often tied to the use in creating various forms of documents (emails, presentations, etc.) that often supersedes the photo's use. These findings reveal opportunities for the design of new techniques to assist in the use and curation of whiteboard photos.

This work provides the following contributions to the field of human-computer interaction:

- empirical evidence of frequent whiteboard users' postmeeting practices involving whiteboard photos,

- $\quad$ empirical evidence of memory recall of characteristics for meetings where a whiteboard was used,

- a lifecycle model describing key individual and groupbased activities involving whiteboard photos, and

- a set of design implications for technologies, including interactive whiteboarding systems, that better support the capture and post-meeting use of whiteboard content.

\section{BACKGROUND}

To set the context for this work, we first overview the motivations for capturing whiteboard photos and prior evidence of this practice. We then discuss possible whiteboard photo management strategies by examining how personal photos are managed. Finally, we review the current level of support for the capture and use of whiteboard photos offered by existing technologies, such as multimedia meeting browsers and whiteboard systems.

\section{Whiteboard Photos as an Output of the Whiteboard}

Tang et al. [44] reported that distinct types of whiteboards support diverse activities. Through observational studies, they identified four kinds of whiteboards spanning the individual to collaborative spectrum: intimate, personal, shared, and public whiteboards. This classification of whiteboards is relevant to the present study because it suggests that the more public the whiteboard is, the more motivation there is to capture its content [3]. A strong motivator for taking pictures of collaboratively created content on public whiteboards is that they exist in locations (e.g., conference rooms) that are away from where people do their independent work (e.g., cubicles and offices).

Personal office whiteboards, in contrast, are close to and visible from where individual work is accomplished, suggesting that photos of personal office whiteboards may be rare. This was confirmed by Branham et al.'s [3] study of personal office whiteboards, in which they found that photographing a whiteboard with a cellphone was perceived as being too time consuming and only happened occasionally. These findings contributed towards shaping the research question of this paper, by directing attention to whiteboard photos of content on public whiteboards taken after a meeting.

Recent studies show examples of ways in which whiteboard photos have been used post-meeting. For example, Walny et al. [45] found two instances in which software developers revisited whiteboard photos taken during a meeting. One developer realized during a meeting that he drew a specific diagram on whiteboards often, so he took a photo of it and recreated it digitally to share with others in the future. Another developer, after a group brainstorming session, took a photo of the whiteboard to serve as a form of agreement, and later uploaded to the group's wiki website. In a study of whiteboard photos taken with a whiteboard capture system called ReBoard, Branham et al. [3] found instances of whiteboard photos being emailed to colleagues, printed to bring to a meeting, and used as a reference to digitally reproduce some of the information.

\section{Management of Photos}

Management of personal photos, email, webpages, and other types of information have received significant attention in the Personal Information Management (PIM) literature. One area of focus has been on understanding the lifecycle of certain types of information. For instance, Whittaker [49] posited that the lifecycle of personal information goes through three distinct curation processes:

1) Keeping (what information is worth keeping),

2) Management (how to manage kept information), and

3) Exploitation (retrieval of information in the future).

This research explores whether Whittaker's curation lifecycle describes the lifecycle of whiteboard photos in the same way that it describes the lifecycle of other personal information. Storage and retrieval practices regarding whiteboard photos are also investigated. This is motivated by Branham et al.'s [3] study of personal office whiteboards which found that people often struggled to find their whiteboard photos because they forgot where they had saved them. Jaimes et al. [13] investigated characteristics of meetings that people remembered well that could be used as retrieval cues of meeting records.

\section{Current Technology Support}

Whiteboard systems can be categorized as: interactive whiteboards, whiteboard capture systems, and mobile applications. Interactive whiteboards require special hardware (TVlike displays that connect to computers) and software (whiteboarding software or meetingware) to mimic and expand the functionality of traditional whiteboards. Users can interact with them with their hands or by using a stylus. One of the first interactive whiteboards was Xerox PARC's LiveBoard [9] running the Tivoli application [33], which was designed to support co-located group meetings. Users could draw on the digital canvas, edit the content, save it, and restore it.

Unlike interactive whiteboards, whiteboard capture systems are traditional whiteboards which have been retrofitted with technology to capture the whiteboard content. For instance, Zombieboard [39] and ReBoard [3] capture content on traditional whiteboards with a digital camera installed in the room which is constantly pointing at the whiteboard. The captured 
whiteboard content stored on the digital camera can be accessed through a web interface from a computer.

With the rise of mobile devices, whiteboard capture system manufacturers like SMART Technologies ${ }^{1}$ have recently started to develop companion mobile applications for their commercial whiteboards. The SMART kapp ${ }^{2}$ whiteboard is a traditional whiteboard which uses small cameras on the edges of the board to record the dry-erase marker's annotations. Captured content is then transferred to the paired SMART kapp app and stored in a library.

Some mobile applications are stand-alone, so they do not require additional hardware to capture whiteboard content. For instance, Evernote ${ }^{\circledR 3}$ and UScanner ${ }^{4}$ use the mobile device's camera directly to capture one or more snapshots of the whiteboard content, and the content is simply stored on the mobile phone.

\section{METHOD}

To investigate the main post-meeting activities that whiteboard photos support, semi-structured interviews were conducted with 19 professionals (P1, P2, .., P19) who regularly use whiteboards in their work.

\section{Sampling and Recruitment}

A purposive sampling strategy was used [31]. The goal of this sampling strategy is to quickly generate insights by "selecting information-rich cases strategically and purposefully" [31, p.343]. This sampling strategy is commonly used when the aim is to learn a great deal about the topic being studied, rather than to generalize from sample to population [31]. Thus, frequent users of whiteboards were sought out, rather than a probabilistic representative sample of whiteboard users. The criteria used to identify them were people who were interested in curating whiteboard photos, had access to whiteboards at work, and used whiteboards regularly (at least once a month)

In addition, a maximum variation sampling strategy [32] was used with respect to the professional background of the required whiteboard users. The goal of this sampling technique is to broaden the range of insights by examining a wide range of cases. Nineteen potential participants who met the criteria (above) were identified in the following three ways:

1) Seven of the participants ( $P 1$ through $P 6$, and $P 18)$ were customers of SMART Technologies who had recently purchased a newly launched dry-erase whiteboard capture system (SMART kapp). These participants were pursued under the presumption that people who spend money on whiteboarding solutions are likely to be regular users of whiteboards,

\footnotetext{
${ }^{1}$ http://smarttech.com/

${ }^{2}$ http://smartkapp.com/

${ }^{3}$ https://evernote.com/

${ }^{4}$ https://u.cyberlink.com/products/uscanner
}

2) Six participants (P7, P8, P11, P12, P13, and P15) were recruited who had participated in a prior whiteboard use study $^{5}$, conducted four months earlier. The researchers of the prior study shared the meeting recordings, so that the participants' recall accuracy of whiteboard content could also be assessed, and

3) In a quasi-snowball sampling fashion [40], the remaining six participants (P9, P10, P14, P16, P17, P19) were recruited by recommendation of other participants.

Of the 19 participants, thirteen were male and six were female. They ranged in age between 18 and 55 and had diverse job titles such as Product Manager, Software Developer, Chartered Accountant, User Experience Researcher, and CEO. They varied widely in seniority ( 1 to 16 years at their organization) and worked in organizations of varying sizes, from start-ups to large companies. These companies were distributed across North America spanning several sectors such as Software and Product Development, Consulting, Biotechnology, and Construction. Thus, a diverse set of people were interviewed to generate a diversity of insights.

\section{Interview Setting and Procedure}

All but two interviews were conducted in person at the participants' workplace in a meeting room. The remaining two interviews took place over the phone (P18), and in the lab of one of the authors (P19). Three sets of participants (P1 \& P2, P3 \& P4, P16 \& P17) were interviewed in pairs as working colleagues. The interviews lasted between 20 and 60 minutes and were audio and video recorded. Using a semi-structured interview protocol, participants were asked several questions related to the methods they used for working with whiteboard photos. The questions spanned topics such as capture, share, store, archive, search, revisit, and re-use of whiteboard photos. To illustrate their practices, participants were asked to describe in detail the actions they took with one or two recently taken whiteboard photos. These descriptions were used to create lifecycle diagrams (described below) during the data analysis phase.

Interviewees were also asked questions related to the utility they derived from their whiteboard photos, and if and how that utility changed over time. In addition, participants were asked to retrieve a sample whiteboard photo and to think aloud while doing so. This allowed the interviewer to observe how the participants approached the retrieval of whiteboard photos, the locations where they kept them, and how those locations were organized (if at all).

\footnotetext{
5 This study was conducted by a different team of researchers from SMART Technologies and collaborative academics who were interested in how traditional whiteboard are used during meetings. The meetings they observed were audio and video recorded.
} 


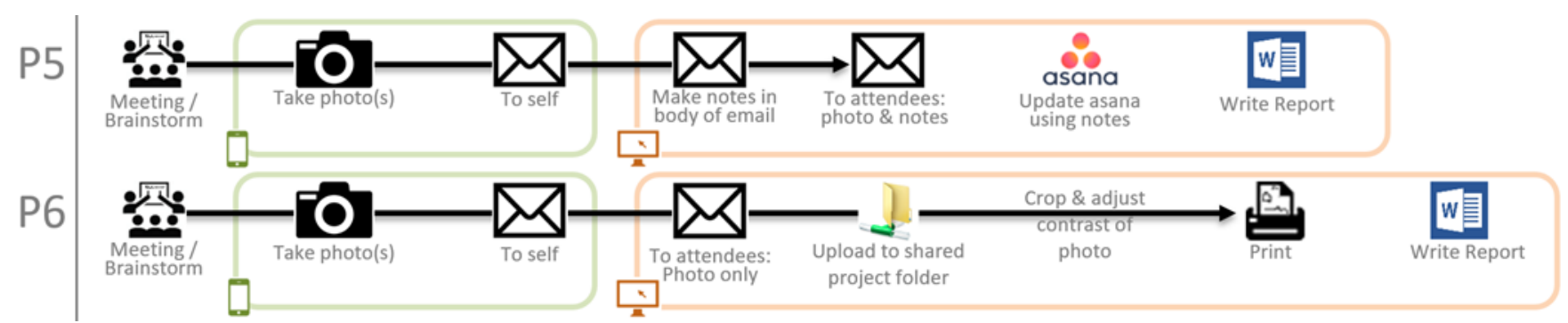

Figure 2. Samples of two different lifecycle diagrams depicting post-meeting usage of whiteboard photos from two participants (P5, P6). The actions located in the green boxes (left) occurred on mobile devices. The actions in the orange boxes (right) occurred on desktop devices. Refer to Figure 3 for a detail legend of the icons.

The six participants who had been involved in the previous observational study of whiteboard use, were asked additional questions probing what they could recall about whiteboard content generated in previous meetings. These questions were included because well-remembered characteristics of whiteboard meetings have the potential to become effective search terms to retrieve whiteboard photos.

After the interview phase, all participants were asked to complete a background questionnaire. The questionnaire asked how often they used whiteboards and whiteboard photos, and basic demographic information such as age group, gender, profession, current employer, and tenure at their current employer. The need to uphold confidentiality prevented the author from obtaining copies of the whiteboard photos and other documents described during the interviews.

The study method was reviewed and approved by the University of Waterloo's institutional ethics review office.

\section{Data Analysis}

Interview data were analyzed using thematic analysis, which involves a six-step process: Familiarize yourself with your data, generate initial codes, search for themes, review themes, define and name themes, and produce a report [4], thematic analysis. The analysis was conducted using interview transcripts on a qualitative data analysis tool called $\mathrm{NVivo}^{6}$. To facilitate transcription of the interview data, the online transcription service called $\mathrm{Rev}^{7}$ was used.

Furthermore, lifecycle diagrams were created to analyze the detailed actions interviewees reported taking with whiteboard photos. Inspiration for the lifecycle diagrams was drawn from Walny et al. [45], who used a similar approach to illustrate the lifecycle of sketches drawn on paper, whiteboards, and notebooks by software developers in an academic research setting. The lifecycle diagrams (Figures 2-4) we created illustrate the capture and use process described by each participant during the interviews. These lifecycles were analyzed for common patterns. The diagrams are also used to aid in the thematic analysis, to illustrate some of the findings, and to develop a general lifecycle framework of whiteboard photos.

\footnotetext{
${ }^{6} \mathrm{http}: / / \mathrm{www} . q$ srinternational.com/product

7 https://www.rev.com/
}

It is important to note that the results of a thematic analysis are qualitative, that is, the responses are not quantified. Quantification in qualitative research is generally discouraged [37, 38]. Furthermore, quantifying responses is particularly difficult to do with data derived from semi-structured interviews. To obtain rich data and insightful narratives during semi-structured interviews, the same questions are not always asked, and when they are, they are not always asked the same way, or in the same order. Often participants indirectly answer a question by way of answering a different question or while giving a narrative. Semi-structured interviews analyzed thematically shed light onto "what", "how", and "why" questions through identification of emergent categories and themes.

Special attention was given to the deviant cases (also called outlier, rare, negative, or extreme cases) because they can offer significant insight into the phenomena of interest [21, 23, 36]. Two types of deviant cases were analyzed, artefacts (whiteboard photos that were valued or used uniquely) and power users (whiteboard users that used whiteboard and whiteboard photos unlike most of the other participants interviewed).

\section{RESULTS}

Following the interview process and data analysis, key findings were identified. These findings aim to answer the overarching research question: What do people do with whiteboard photos after a meeting? However, to give context to these identified practices, the interviews revealed key insights about what was captured during the meetings.

\section{Capturing (and Over-capturing) Whiteboard Content}

Participants described meetings in which the content written on the whiteboard was deemed worthy of capture. Commonly, these meetings produced whiteboard content "that's specific and has tasks that you want to go forward with, or decisions that you want to move forward" (P5) and is thus important enough to be photographed. Typically, the person responsible for managing the whiteboard content post-meeting is the only person who takes a photo of the whiteboard.

The analysis revealed that participants struggled with determining whether whiteboard content was important enough to 
merit capture. Participants coped with this uncertainty by over-capturing whiteboard content "just in case" it turned out to be useful later. As P11 and P15 explained:

"In some cases, it's almost like a security blanket to take a photo of what happened." (P11)

"A lot of the time I'll take a photo just to know that I have it, but I don't really need to distill the information." (P15)

A consequence of this over-capturing behaviour was that some (sometimes many) whiteboard photos were never used. As P18 expressed, "I'll tell you the truth, I probably use my phone to take a picture of a lot of whiteboards, and I've never looked back on them."

\section{Difficult to Transfer Whiteboard Photos}

Before working with whiteboard photos, all participants reported first transferring the whiteboard photos from their mobile phones to a location accessible by a productivity-oriented device such as a desktop or a laptop computer. Participants transferred whiteboard photos off their phones in one of three ways: 1) email to self (most common), 2) auto-synchronize to a personal cloud-based folder, or 3) AirDrop ${ }^{{ }_{8}}$ for Mac OSX users. Transferring the whiteboard photo was found to be a significant pain point for participants, as illustrated by the following comments:

"I will love if I could just save directly to OneDrive ${ }^{\circledR 9}$. Today I must send a copy by mail, and from there I must forward it to the team." (P13)

"We might write the JIRA ${ }^{\circledR} 10$ task number on the board and then that would be perfect if you could make the photo attach itself automatically to that JIRA ${ }^{\circledR}$ task, that would be sweet." (P1)

"It would work great if you could upload your whiteboard content directly to the Asana ${ }^{\circledR 11}$ network." (P5)

"If you could hit a button on the whiteboard to say, 'I'm done', and it captured that like when you scan to PDF on a multifunction copier. That would be pretty cool." (P6)

\section{The Superseding Document}

The most common way participants used whiteboard photos was as references when creating another more formal document such as a Microsoft ${ }^{\circledR}$ PowerPoint presentation, a Microsoft $^{\circledR}$ Word/OneNote document, or an email to the other meeting attendees. We refer to this other document as a superseding document, because whiteboard photos were found to lose most of their utility after this document was created.

Participants reported that they rarely imported the whiteboard photo into the superseding document as they were creating it. Instead, they would typically "have the image open on my one monitor, and then the document open on the

\footnotetext{
${ }^{8}$ Apple AirDrop ${ }^{\circledR}$ is a user-initiated file transfer method between Macintosh computers and iOS devices

${ }^{9}$ Microsoft's service for hosting files in the cloud. http://onedrive.live.com
}

other" (P7). Two participants also mentioned using a printed version of the whiteboard photo, as illustrated by the comment "I cropped it, framed it, contrast adjustment and printed it as a reference for myself while I was writing the grant application in Microsoft ${ }^{\circledR}$ Word" (P6). With both documents open, people then extracted the important content from the whiteboard photo into the superseding document.

The extraction process was more complex than just duplicating the words and diagrams found in the photo verbatim in the superseding document, as illustrated by the comment, "I would try to put the brainstorming ideas into meaningful categories in Word, because in the raw form whiteboard photo, they were all over the place, and I couldn't really group them. In the Word document is where I was able to make meaning of them" (P7). Participants reported extracting some or all the content on a whiteboard photo "and then building out more detail in the document" (P8) using their memory of the conversations during the meeting.

Two main sources of frustration for people in creating the superseding document from the whiteboard photo were: 1) recreating textual and drawn content into digital form into the document, and 2) knowing when they had extracted all the useful information from the whiteboard photo. The most commonly reported superseding document created using a whiteboard photo was an email to send to the meeting attendees.

\section{The Ephemeral Value of Most Whiteboard Photos}

By far, the most common criterion participants reported in determining a whiteboard photo's importance was its recency, as illustrated by the following comments:

"I'd just keep the most recent whiteboard photos." (P5)

"The more recent stuff is more important... I guess a way to organize them would be maybe chronologically." (P8)

"I would save the most recent photos." (P19)

"I'd say eight weeks out and the whiteboard photo probably isn't relevant anymore." (P11)

The data revealed that one of the reasons that recent whiteboard photos were the most important was because whiteboard photos were primarily valued on their ability to inform a superseding document, which was usually created shortly after a meeting. Participant comments illustrated this finding, "Rarely do I find the image itself useful other than transcribing the data" (P15), and "If the whiteboard photo hasn't been carried forward into a future document, then it probably wasn't important" (P4). Even though superseding documents often rendered whiteboard photos obsolete, for some people, whiteboard photos were still worth keeping if they were part of an ongoing project.

\footnotetext{
${ }^{10} \mathrm{Bug}$ and issue tracking software which is popular amongst agile software development teams. https://www.atlassian.com/software/jira

${ }^{11}$ Task tracking software for teams. https://asana.com
} 
Some participants described a whiteboard photo that was particularly important to them and they would be devastated if they lost it while a project was active. These highly valued photos tended to be the result of extensive group work not documented anywhere else. Further analysis of the data revealed that these "special" whiteboard photos had the following common characteristics: They were dense with ink (lots of detail) and they contained graphical elements (sketches and illustrations, not just hand-written words). These special whiteboard photos tended to come from meetings which had the following common characteristics: They were lengthy (often lasting several hours), several people wrote on the whiteboard and for the purpose of creation or ideation (as opposed to explanation or note-taking).

These special whiteboard photos were consulted regularly and retained significant value throughout the life of the project, as P8 explained: "When notes on a whiteboard are created as part of some type of analysis or synthesis of a research study, for instance, then I tend to go back to it many more times than just once".

\section{Management of Whiteboard Photos}

The analysis revealed various strategies for managing whiteboard photos, including storage locations, and how they were retrieved and eventually discarded.

The interview data revealed that participants kept several duplicate copies of the same whiteboard photos at several storage locations. These storage locations were more commonly personal than shared. The top three personal storage locations reported by participants were the camera roll in their mobile phone, email, and cloud-based folders. The camera roll became a storage location as a result of capturing whiteboard content. Email became a storage location as it was the most common way participants transferred the photo off their mobile phones (email to self), and the most common way whiteboard photos were shared with attendees. Most personal cloud-based folders became a storage location automatically, as participants reported that their mobile phone's camera roll automatically uploaded all their photos to the cloud. Additionally, a few participants (P6, P10, P14) mentioned printing some whiteboard photos and placing them on their desks or pinning them up on nearby walls or partitions. Only one participant (P17) reported adding whiteboard photos to his Evernote ${ }^{\circledR}$.

In addition to personal storage locations, whiteboard photos were sometimes stored in shared locations. Storing to a shared location typically occurred after an email had been sent to the attendees. The most commonly reported shared storage location was a folder, either on a network drive or a cloud service such as OneDrive ${ }^{\circledR}$. Less commonly reported, important whiteboard photos were stored in collaboration tools such as $\mathrm{JIRA}^{\circledR}(\mathrm{P} 1, \mathrm{P} 2$, and P15) where they were attached to tasks and Slack ${ }^{\circledR} 12$ (P11). From there, whiteboard photos were uploaded to a dedicated whiteboard photo channel such as "\#design_whiteboards".

When whiteboard photos were added to folders, people sometimes renamed the file from the arbitrary filename created by the mobile phone image software, to a name with meaningful metadata. As P7 stated, "It can't just be 'Image 07196"'. A commonly reported naming convention included the meeting date and a few words describing what the whiteboard content or the meeting was about. A few participants suggested solutions to aid the renaming of the filename of whiteboard photos, such as P9 who said, "Just the ability at the moment when it exports out as a photo, that you must name it something. It can't just be image 07196, and then the date is automatically attached. That would be much more helpful." Some participants had even more elaborate suggestions such as automatically naming the file by extracting the title from the "the subject of the meeting invite" (P10), or from the whiteboard content itself if there was a title and it was "double underlined" (P6).

\section{Lifecycle of Whiteboard Photos}

A key objective of this research was to better understand the lifecycle of whiteboard photos. As aforementioned, lifecycle diagrams were created illustrating the capture and use process described by each participant during the interviews (Figure 3 (top), lifecycle diagrams for all but P1 and P10, which are shown in Figure 4). For two participants (P6 and P8), who reported handling whiteboard photos differently depending on circumstances and what tools were available, multiple lifecycle diagrams were created (Figure 3 (P6-1, P62, P8-1, P8-2)).

The individual lifecycles were then analyzed for common patterns. This analysis revealed that whiteboard photos generally go through a seven-stage lifecycle: Capture, transfer, extract to attendees, share, store, extract to self, and forget (Figure 3 (bottom)).

Capture

All interviewees reported capturing whiteboard content in a photo using the integrated camera on their mobile phones.

\section{Transfer}

After capturing, all interviewees reported transferring the whiteboard photo from the mobile phone to a location accessible via a desktop computer or laptop. The most common practice was to send an email to themselves. Participants rarely shared the whiteboard photos from their mobile phones with others. The remaining four stages occurred on a productivity-oriented device such as a desktop or laptop computer.

\section{Extract for attendees}

The most commonly reported action taken after transferring the photo was extracting its information into a superseding document. This document was almost always an email which 


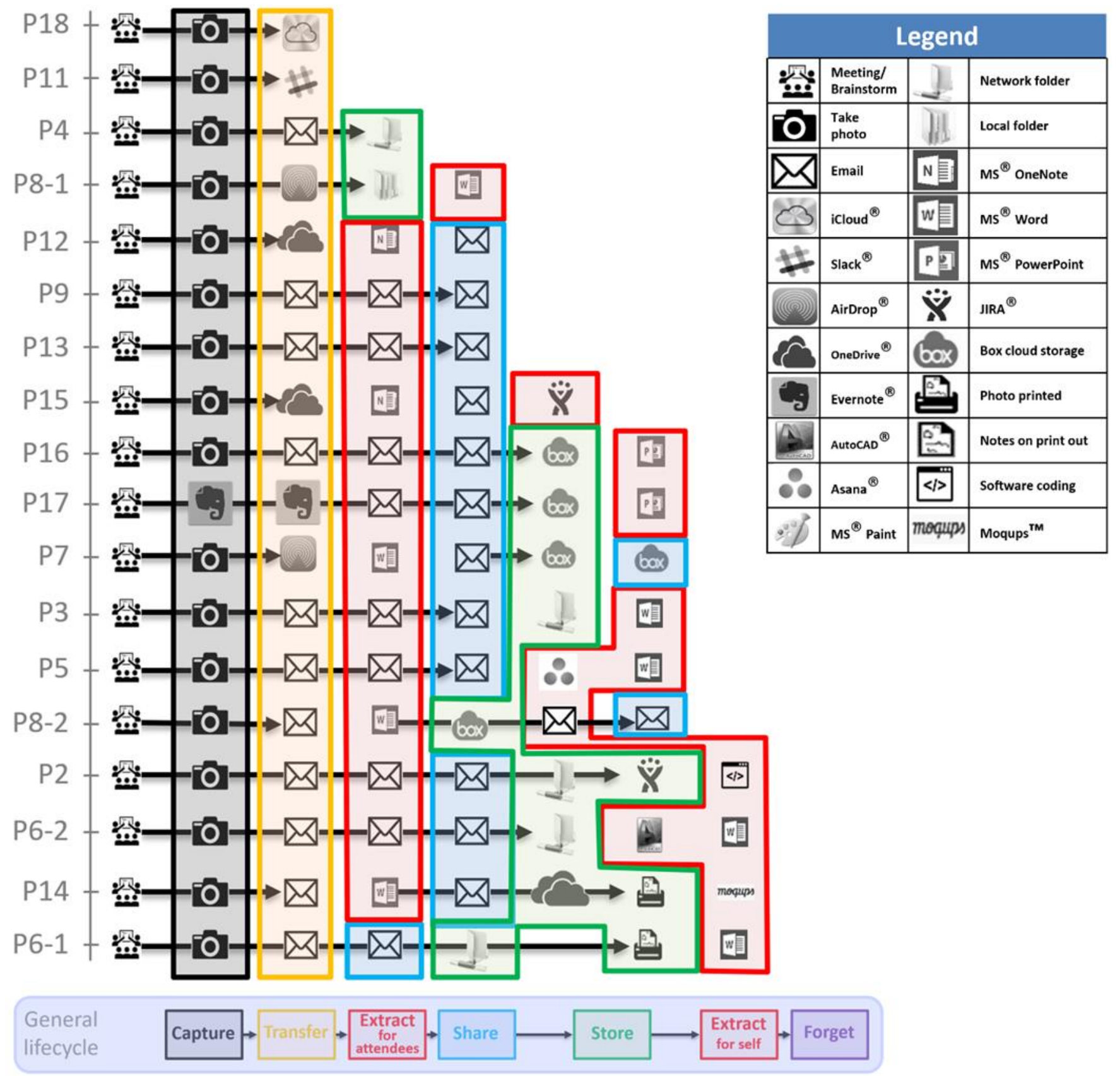

Figure 3. Individual (top rows) and general (bottom row) lifecycle diagrams. Lifecycle diagrams are shown for all participants, excluding P1 and P10. Two lifecycle diagrams are shown for P6 and P8 to represent the two different practices they each reported.

was later sent to the meeting attendees (next stage), indicating that the extracted information was oriented towards team coordination (e.g., summarizing meeting outcomes, and action items). Less commonly, the information was extracted into a word processor such as a Microsoft ${ }^{\circledR}$ Word document.

\section{Share}

After extraction, the most common action participants reported taking was sending an email to the meeting attendees with the extracted information. When the extracted information was in the body of an email, the whiteboard photo was almost always attached. However, when the information was extracted to a word processor, the word document was typically attached to the email, but not the whiteboard photo.

\section{Store}

After sharing, the most common action participants reported taking was storing the whiteboard photo, typically in a shared project folder.

\section{Extract for self}

After storing the photo, the most common action participants reported taking was once again extracting information from 
it (e.g., to a PowerPoint presentation or a Word document, but rarely an email). The extracted information, at this stage, was generally for individual work activity.

\section{Forget}

While not explicitly an action that participants mentioned when describing the lifecycles of whiteboard photos, the interview data revealed that the last stage was inaction to discard the whiteboard photos. Given the abundance of inexpensive data storage capabilities of most desktop computers or cloud storage devices and its lack of value after the extraction process, simply forgetting about the whiteboard photo was a realistically feasible behaviour.

\section{Power Users}

The capture and use process described by each interviewee revealed common patterns that assisted in establishing the general lifecycle model discussed above. However, the analysis also revealed distinct "power users" who utilized whiteboard photos differently from other people. Specifically, two participants (P1 and P10) stood out as power users of whiteboards and whiteboard photos. Some of the power user behaviours also applied to participants like P8 and P13, while only a few of these behaviours applied to participants P11 and P15. None applied to participants P7, P5 and P18. This suggests that there was a continuum of power users, at least among our study participants. The following characteristics of power users and how they use whiteboard content, were identified:

- Whiteboards and whiteboard content are critical tools for power users,

- Power users used whiteboards and whiteboard photos frequently (more than once a month), and

- Power users have developed specific processes over the years for managing whiteboard photos.

Figure 4 shows the whiteboard photo lifecycle diagrams for power users. A few additional steps can be identified in the power user whiteboard photo lifecycles. For instance, the whiteboard photos used by $\mathrm{P} 1$ remain part of the working document, and only reaches the forgotten stage once the project is complete. P10 cleans up and refines the information on the whiteboard before capturing it. The general lifecycle described above, however, still applies to both power user whiteboard photo lifecycles, but with additional activities added to improve the process.

\section{Recall of Whiteboard Content}

Finally, we reviewed the data from the memory recall task performed by the subset of interviewees who were involved in a prior study of whiteboard use. Table 1 summarizes the results of these data. Consistent with Jaimes et al.'s [13] findings, these data show that interviewees could readily recall general characteristics about the meeting and whiteboard content (e.g. topic of meeting, meeting attendees, and location of meeting), but had more difficulty recalling specific details about the whiteboard content generated during the meeting. This finding has implications for post-meeting photo retrieval as discussed below.

Table 1. Summary of memory recall task.

\begin{tabular}{|c|c|}
\hline $\begin{array}{l}\text { Easily recalled character- } \\
\text { istics }\end{array}$ & $\begin{array}{l}\text { Characteristics difficult to } \\
\text { correctly recall }\end{array}$ \\
\hline Meeting room & $\begin{array}{l}\text { What colors markers were used on } \\
\text { the whiteboard }\end{array}$ \\
\hline Topic of meeting & $\begin{array}{l}\text { Parts or quadrants of the whiteboard } \\
\text { used }\end{array}$ \\
\hline $\begin{array}{l}\text { Meeting attendees (although } \\
\text { people struggled to recall all at- } \\
\text { tendees if }>8 \text { attendees) }\end{array}$ & $\begin{array}{l}\text { Density/percentage of the white- } \\
\text { board used }\end{array}$ \\
\hline $\begin{array}{l}\text { Attendees who drew on the } \\
\text { whiteboard }\end{array}$ & $\begin{array}{l}\text { Major or complete erasures of the } \\
\text { board during the meeting }\end{array}$ \\
\hline \multirow[t]{2}{*}{$\begin{array}{l}\text { Was diagrammatic content } \\
\text { (non-text sketches) written on } \\
\text { the whiteboard }\end{array}$} & $\begin{array}{l}\text { What sketches drawn on a white- } \\
\text { board were about or what they } \\
\text { looked like }\end{array}$ \\
\hline & $\begin{array}{l}\text { Who the photos were shared with } \\
\text { after the meeting (if shared at all) }\end{array}$ \\
\hline
\end{tabular}

\section{DISCUSSION}

In this section, we discuss our findings in the broader research context regarding whiteboard studies, meeting records, and information management of personal photos. We also present several opportunities for design that step from this work.

\section{Whiteboard Photos as a Meeting Record}

The way participants described extracting information from whiteboard photos to create superseding documents resembled the information salvaging behaviour described by Moran et al. [25]. Like audio records, the content of whiteboard photos was not easily consumable, which forced people to engage in this salvaging activity as an active process of sense-making that is more involved than mere information consumption.

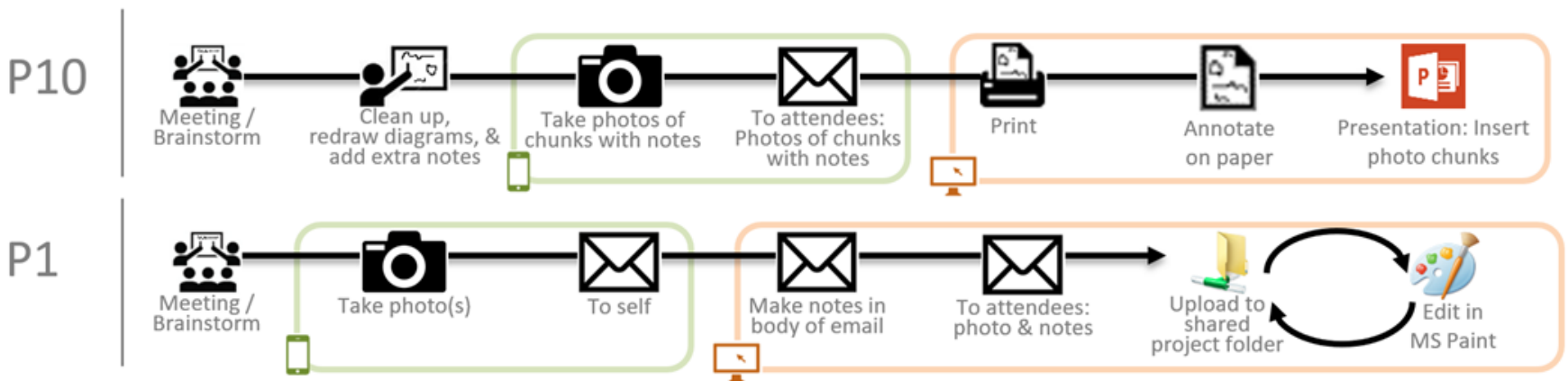

Figure 4. Whiteboard photo lifecycle diagrams of power users (P1 and P10). 
Consistent with Jaimes et al. [13], this research found that whiteboard photos were a general meeting record that was used to support group activities. For instance, whiteboard photos served as evidence of agreement which could be used to settle disputes between team members arising from later interpretation of meeting outcomes. Although whiteboard photos were typically taken by one group member with a personal cellphone, the photos were perceived by participants to be collectively owned by the group and served as group memory. As a result, whiteboard photos were often shared through email with meeting attendees and stored in shared locations such as team project folders. Unlike a personalized redrawing of a diagram in a notebook by a meeting attendee which is subject to recopying errors, the photographic medium of whiteboard photos was well-suited as a consensual evidentiary record because it is not biased.

However, whiteboard photos also supported activities normally supported by personal meeting records. For instance, Whittaker et al. [47] found that personal meeting records were used "to provide enough contextual information to carry out personal actions" [47, p7] and this research found that a key personal action that whiteboard photos enabled was creating a superseding document. Moreover, consistent with Whittaker's finding that personal meeting records were used "to check the accuracy of the minutes" [47, p7], this research found that whiteboard photos were used to check the accuracy of superseding documents. Finally, like personal meeting notes, whiteboard photos were found to be most valuable in the short-term [15].

\section{Curation of Whiteboard Photos Differs from the Curation of Personal Photos}

Even though whiteboard photos and personal photos share the same photographic medium, this research found that whiteboard photos were valued differently than personal photos. For instance, people's archives of personal photos were perceived to be very important and irreplaceable [35, 48], whereas this research found that many participants did not care if they lost their whiteboard photos after they were replaced by another document. Moreover, this research found that whiteboard photos were most valuable in the short-term (days to a few weeks). Their value quickly faded and became obsolete when the project ended. In contrast, previous research has found that personal photos are valuable in both the short-term (to show friends photos of a recent vacation) and the long-term and may increase in value over time (baby pictures or photos of ancestors) [34].

Due to these differences, the study results revealed a key difference between the lifecycle of whiteboard photos and Whittaker's [49] and Bernstein et al.'s [1] lifecycles of personal photos. Their lifecycles describe long-term actions, such as photo management and repeated exploitation, that do

\footnotetext{
13 These systems typically capture whiteboard content using the camera of a mobile device at discrete times (i.e., users decide when to capture, typically at the end of a meeting, as this research showed).
}

not feature in the lifecycle of whiteboard photos. This difference stems from the short-term value placed on whiteboard photos by the participants in this study, and their value as proxy artifacts for the ideas created during the group meetings. Our whiteboard photo lifecycle model captures these points in the "extract" (for attendees and for self) stages (showing its proxy role), as well as the final "forget" stage (showing the depreciated value).

\section{Opportunities for Design}

Mobile-centric whiteboard capture systems ${ }^{13}$ are most applicable to the context studied. However, the results also have implications for whiteboard-centric capture systems ${ }^{14}$. The ability to capture whiteboard content continuously during a meeting provides additional opportunities to support postmeeting use of whiteboard content.

It was found that the first two stages (capture and transfer) in the lifecycle of whiteboard photos involved a mobile device while the remaining stages involved a productivity-oriented device such as a desktop computer. Consistent with this finding, a mobile-centric whiteboard capture system aiming to improve this current practice would involve a mobile application and a desktop application.

\section{Mobile-centric: Implications for a Mobile Application}

The mobile application should support quick capture. This implies that users should be able to capture whiteboard content with a mobile application as fast as or faster than they can already capture whiteboard content with the native camera photo application on a mobile device.

The research findings also suggest that a better whiteboard photo transfer and storage mechanism is needed. "Better" transfer and storage techniques would be quicker and require fewer steps from the user. For instance, right after users capture whiteboard content, the mobile application could prompt the user to transfer the photo, or automatically transfer the photo so that no action is required by the user. This research also found that whiteboard photos were transferred to a variety of storage locations, including email, shared cloud folders, and collaboration tools like Slack ${ }^{\circledR}$, and JIRA ${ }^{\circledR}$. Participants reported that transferring the photo to these accessible locations was effortful. This implies that better integration is needed so that users can easily transfer whiteboard photos to their desired storage location. Automatic photo file renaming (e.g., adding the meeting date, time, location or participants to the file name) could also be incorporated to streamline and improve the process.

\section{Mobile-centric: Implications for a Desktop Application}

The desktop application should support extraction and creation of a superseding document. The primary way in which participants used whiteboard photos was to create a document by extracting the useful information from the white-

\footnotetext{
14 These systems use capture mechanisms such as special marker casings or cameras attached to the board or the meeting room. Content is captured continuously throughout the meeting.
} 
board photo and expanding on it in the document. This extraction, which was a reported pain point, always happened on productivity-oriented devices such as a desktop or a laptop computer. Together, these findings imply that users would benefit from a desktop application that simplified the extraction process. However, the extraction of information from the whiteboard photo to the superseding document was not a matter of simply extracting every word from the whiteboard photo and copying it to the superseding document. The extraction process was similar to the active sense-making behaviour of salvaging described by Moran et al. [25]. Thus, this extraction process should be cultivated in an enhanced extraction solution, which does not merely extract all the content, only pertinent information. In Figure 5, the content in black may be relevant for the extraction task, but not the surrounding text. A fully automated extraction process may mistakenly extract everything.

Participants were found to over-capture whiteboard content just in case some of it turned out to be useful later. Power users were also found to have more whiteboard photos than other users due to how frequently they used whiteboards and how frequently they captured whiteboard content. A design implication is to manage whiteboard photos in such a way that it does not increase the management burden on users. Moreover, unlike personal photos, which people keep primarily for their sentimental value and affective properties $[49,34]$, this research found that many whiteboard photos had actionable properties. Users were usually required to do something with them by a certain date. According to Whittaker [49], action-oriented information typically benefits from features like reminders. Therefore, associating calendars or to-do list-type action properties to whiteboard photos may help users better manage these artefacts.

Power users were found to use some whiteboard photos in the long-term and reported that retrieving whiteboard photos was sometimes a pain point. The findings from the memory task revealed that most people remembered typical characteristics of a previous meeting but not characteristics of the whiteboard content itself. Based on these findings, one way to improve the retrieval of whiteboard photos for power users would be to associate it with the topic of the meeting, attendees, and meeting location so that they can be used as

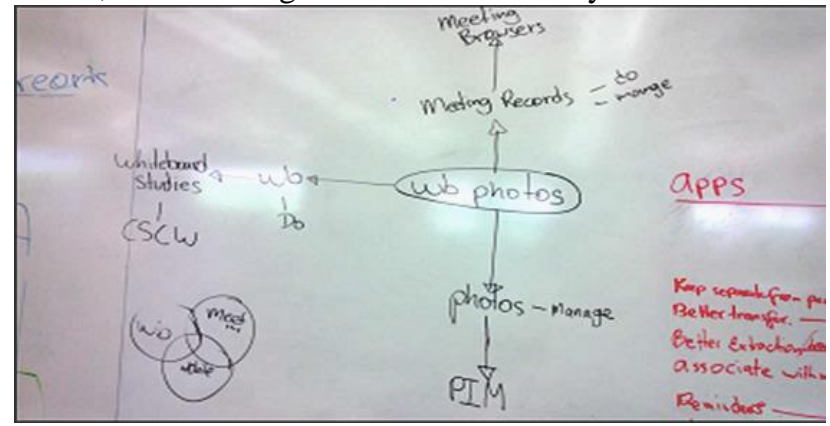

Figure 5. A sample whiteboard photo where some content (e.g. black text in center) would be relevant for extraction, and some would not (e.g., red text on right, blue text on left). search terms. This information could be extracted from calendars given that meeting invites usually contain the topic of the meeting, the time, attendees, and the location of the meeting. In this potential solution, when a whiteboard photo is taken, the mobile application would check the user's calendar application to see if he or she is currently scheduled to be in a meeting or if a meeting just ended.

\section{Whiteboard-centric}

Utilizing a whiteboard-centric capture system changes some of the aspects of the whiteboard photo lifecycle. Namely, the explicit capture stage may be eliminated completely if the system automatically and continuously captures content. However, depending on where the system stores the captured content, the transfer stage may still need to be supported.

One implication stemming from the finding that whiteboard photos were used as a form of evidence and shared understanding, is that whiteboard-centric capture systems should enhance this ability. This ability is available in some systems (e.g., DUMMBO [5]), but usually for reminding meeting attendees what happened during a meeting, not as an enhanced form of evidence. Another potential way that whiteboard systems could enhance their evidentiary utility is to capture who wrote what on the whiteboard during the meeting so that users could easily review this information post-meeting using a desktop application.

\section{CONCLUSION}

This paper investigated the post-meeting curation of whiteboard content captured with mobile devices to inform the design of future whiteboard capture systems. The research findings led to a deeper understanding of the main post-meeting activities that whiteboard photos support, how users value whiteboard photos, and how whiteboard photos are managed. This knowledge led to the creation of a general lifecycle of whiteboard photos, along with identification of some additional practices that "power users" have developed to optimize their use of whiteboard content. Finally, we discussed potential design implications for the design of mobile, desktop, and whiteboard capture system application tools to better support the capture and post-meeting use of whiteboard content. How participants deal with whiteboard content when collaboration extends beyond observed meetings, was not investigated. This could form part of a future research project.

\section{ACKNOWLEDGEMENTS}

This research was funded in part by MITACS, Smart Technologies, Inc., and the Natural Sciences and Research Council of Canada (NSERC). We gratefully acknowledge our study participants, and also Andy Cargile, who assisted with site access and guided the research throughout. We also gratefully acknowledge the support and feedback of the Waterloo EngHCI research group throughout this research. 


\section{REFERENCES}

1. Bernstein, M., Van Kleek, M., Karger, D., \& Schraefel, M. C. (2008). Information scraps: How and why information eludes our personal information management tools. ACM Transactions on Information Systems (TOIS), 26(4), 24.

2. Brandl, P., Haller, M., Oberngruber, J., \& Schafleitner, C. (2008, May). Bridging the gap between real printouts and digital whiteboard. In Proceedings of the working conference on Advanced visual interfaces (pp. 31-38). ACM.

3. Branham, S., Golovchinsky, G., Carter, S., \& Biehl, J. T. (2010, April). Let's go from the whiteboard: supporting transitions in work through whiteboard capture and reuse. In Proceedings of the SIGCHI Conference on $\mathrm{Hu}$ man Factors in Computing Systems (pp. 75-84). ACM.

4. Braun, V., \& Clarke, V. (2006). Using thematic analysis in psychology. Qualitative research in psychology, 3(2), 77-101.

5. Brotherton, J. A., Abowd, G. D., \& Truong, K. N. (1999). Supporting capture and access interfaces for informal and opportunistic meetings.

6. Brown, B. A., Sellen, A. J., \& O'hara, K. P. (2000, April). A diary study of information capture in working life. In Proceedings of the SIGCHI conference on Human Factors in Computing Systems (pp. 438-445). ACM.

7. Chiu, P., Kapuskar, A., Reitmeier, S., \& Wilcox, L. (1999, October). NoteLook: Taking notes in meetings with digital video and ink. In Proceedings of the seventh ACM international conference on Multimedia (Part 1) (pp. 149-158). ACM.

8. Cutler, R., Rui, Y., Gupta, A., Cadiz, J. J., Tashev, I., He, L. W., ... \& Silverberg, S. (2002, December). Distributed meetings: A meeting capture and broadcasting system. In Proceedings of the tenth ACM international conference on Multimedia (pp. 503-512). ACM.

9. Elrod, S., Bruce, R., Gold, R., Goldberg, D., Halasz, F., Janssen, W., Lee, D., McCall, K., Pedersen, E., Pier., K., Tang, J., \& Welch., B. (1992, June). Liveboard: a large interactive display supporting group meetings, presentations, and remote collaboration. In Proceedings of the SIGCHI conference on Human factors in computing systems (pp. 599-607). ACM.

10. Gumienny, R., Gericke, L., Quasthoff, M., Willems, C., \& Meinel, C. (2011, June). Tele-Board: Enabling efficient collaboration in digital design spaces. In Computer Supported Cooperative Work in Design (CSCWD) (pp. 47-54). IEEE.

11. Haller, M., Leitner, J., Seifried, T., Wallace, J. R., Scott, S. D., Richter, C., Brandl., P., Gokcezade., A., \& Hunter, S. (2010, April). The nice discussion room: Integrating paper and digital media to support co-located group meetings. In Proceedings of the SIGCHI Conference on Human Factors in Computing Systems (pp. 609618). ACM.
12. Ishii, H., \& Kobayashi, M. (1992, June). ClearBoard: a seamless medium for shared drawing and conversation with eye contact. In Proceedings of the SIGCHI conference on Human factors in computing systems (pp. 525532). ACM.

13. Jaimes, A., Omura, K., Nagamine, T., \& Hirata, K. (2004, October). Memory cues for meeting video retrieval. In Proceedings of the the 1st ACM workshop on Continuous archival and retrieval of personal experiences (pp. 74-85). ACM.

14. Ju, W., Ionescu, A., Neeley, L., \& Winograd, T. (2004, November). Where the wild things work: capturing shared physical design workspaces. In Proceedings of the 2004 ACM conference on Computer supported cooperative work (pp. 533-541). ACM.

15. Khan, F. (1993). A survey of note-taking practices. Hewlett-Packard Laboratories.

16. Klokmose, C. N., \& Bertelsen, O. W. (2013). The Mysterious Whiteboard. In Human-Computer InteractionINTERACT 2013 (pp. 37-54). Springer Berlin Heidelberg

17. Lee, D. S., Erol, B., Graham, J., Hull, J. J., \& Murata, N. (2002, December). Portable meeting recorder. In Proceedings of the tenth ACM international conference on Multimedia (pp. 493-502). ACM.

18. Lee, D. S., Hull, J. J., Erol, B., \& Graham, J. (2004, June). Minuteaid: multimedia note-taking in an intelligent meeting room. In Multimedia and Expo, 2004. ICME'04. 2004 IEEE International Conference on (Vol. 3, pp. 1759-1762). IEEE.

19. Lee, B., Kazi, R. H., \& Smith, G. (2013). SketchStory: Telling more engaging stories with data through freeform sketching. Visualization and Computer Graphics, IEEE Transactions on Visualization and Computer Graphics, 19(12), 2416-2425.

20. Lindlbauer, D., Haller, M., Hancock, M., Scott, S. D., \& Stuerzlinger, W. (2013, October). Perceptual grouping: selection assistance for digital sketching. In Proceedings of the 2013 ACM international conference on Interactive tabletops and surfaces (pp. 51-60). ACM.

21. Madill, A., Jordan, A., \& Shirley, C. (2000). Objectivity and reliability in qualitative analysis: Realist, contextualist and radical constructionist epistemologies. British journal of psychology, 91(1), 1-20.

22. Mangano, N., LaToza, T. D., Petre, M., \& van der Hoek, A. (2014, April). Supporting informal design with interactive whiteboards. In Proceedings of the SIGCHI Conference on Human Factors in Computing Systems (pp. 331-340). ACM.

23. Miles, M. B., \& Huberman, A. M. (1994). Qualitative data analysis: An expanded sourcebook. Sage.

24. Moran, T. P., Chiu, P., Harrison, S., Kurtenbach, G., Minneman, S., \& Van Melle, W. (1996, November). Evolutionary engagement in an ongoing collaborative work process: A case study. In Proceedings of the 1996 ACM conference on Computer supported cooperative work (pp. 150-159). ACM. 
25. Moran, T. P., Palen, L., Harrison, S., Chiu, P., Kimber, D., Minneman, S., van Melle, W., \& Zellweger, P. (1997, March). "I'll get that off the audio": a case study of salvaging multimedia meeting records. In Proceedings of the ACM SIGCHI Conference on Human factors in computing systems (pp. 202-209). ACM.

26. Moran, T. P., \& van Melle, W. (2000, April). Tivoli: integrating structured domain objects into a freeform whiteboard environment. In $\mathrm{CHI}^{\prime} \mathrm{OO}$ extended abstracts on Human factors in computing systems (pp. 20-21). ACM.

27. Mynatt, E. D. (1999). The writing on the wall. In Proceedings of the 7th IFIP Conference on Human-Computer Interaction.

28. Mynatt, E. D., Igarashi, T., Edwards, W. K., \& LaMarca, A. (1999, May). Flatland: new dimensions in office whiteboards. In Proceedings of the SIGCHI conference on Human Factors in Computing Systems (pp. 346-353). ACM.

29. Pao, S. Y., Reben, A., \& Larson, K. (2012, November). FlickInk: bridging the physical and digital for creative work. In SIGGRAPH Asia 2012 Emerging Technologies (p. 9). ACM.

30. Patton, M. Q. (1999). Enhancing the quality and credibility of qualitative analysis. Health services research, 34(5 Pt 2), 1189.

31. Patton, M. Q. (2002). Qualitative interviewing. Qualitative research and evaluation methods, 3, 344-347.

32. Patton, M. Q. (2005). Qualitative research. John Wiley \& Sons, Ltd.

33. Pedersen, E. R., McCall, K., Moran, T. P., \& Halasz, F. G. (1993, May). Tivoli: An electronic whiteboard for informal workgroup meetings. In Proceedings of the INTERACT'93 and CHI'93 conference on Human factors in computing systems (pp. 391-398). ACM.

34. Petrelli, D., Bowen, S., \& Whittaker, S. (2014). Photo mementos: Designing digital media to represent ourselves at home. International Journal of Human-Computer Studies, 72(3), 320-336.

35. Petrelli, D., Whittaker, S., \& Brockmeier, J. (2008). Autotopography: What can physical mementos tell us about digital memories? Proceedings of the ACM SIGCHI Conference on Human Factors in Computing Systems, 53-62.

36. Pope, C., Ziebland, S., \& Mays, N. (2000). Analysing qualitative data. British Medical Journal, 320(7227), 114-116.

37. Pratt, M. G. (2008). Fitting oval pegs into round holes tensions in evaluating and publishing qualitative research in top-tier North American journals. Organizational Research Methods, 11(3), 481-509.

38. Pratt, M. G. (2009). From the editors: For the lack of a boilerplate: Tips on writing up (and reviewing) qualitative research. Academy of Management Journal, 52(5), 856-862.

39. Saund, E. (1999). Bringing the marks on a whiteboard to electronic life. In Cooperative Buildings. Integrating
Information, Organizations, and Architecture (pp. 69 78). Springer Berlin Heidelberg.

40. Singh, L., Bienenstock, E. J., \& Mann, J. (2010). Perspectives on Social Network Analysis for Observational Scientific Data. In Handbook of Social Network Technologies and Applications (pp. 147-168). Springer US.

41. Sra, M., Lee, A., Pao, S. Y., Jiang, G., \& Ishii, H. (2012, October). Point and share: from paper to whiteboard. In Adjunct proceedings of the 25th annual ACM symposium on User interface software and technology (pp. 2324). ACM.

42. Stefik, M., Foster, G., Bobrow, D. G., Kahn, K., Lanning, S., \& Suchman, L. (1987). Beyond the chalkboard: computer support for collaboration and problem solving in meetings. Communications of the ACM, 30(1), 32-47.

43. Suchman, L. A. 1988. Representing practice in cognitive science. Human Studies, 11(2-3), 305-325.

44. Tang, A., Lanir, J., Greenberg, S., \& Fels, S. (2009, May). Supporting transitions in work: informing large display application design by understanding whiteboard use. In Proceedings of the ACM 2009 International Conference on Supporting Group Work (pp. 149-158). ACM.

45. Walny, J., Haber, J., Dörk, M., Sillito, J., \& Carpendale, S. (2011, September). Follow that sketch: Lifecycles of diagrams and sketches in software development. In VISSOFT 2011: Proceedings of International Workshop on Visualizing Software for Understanding and Analysis. IEEE.

46. Wellner, P., Flynn, M., \& Guillemot, M. (2004). Browsing recorded meetings with Ferret. In Machine Learning for Multimodal Interaction (pp. 12-21). Springer Berlin Heidelberg.

47. Whittaker, S., Laban, R., \& Tucker, S. (2006). Analysing meeting records: An ethnographic study and technological implications. In Machine Learning for Multimodal Interaction (pp. 101-113). Springer Berlin Heidelberg.

48. Whittaker, S., Bergman, O., \& Clough, P. (2010). Easy on that trigger dad: a study of long term family photo retrieval. Personal and Ubiquitous Computing, 14(1), 31-43.

49. Whittaker, S. (2011). Personal information management: from information consumption to curation. Annual review of information science and technology, 45(1), 1-62.

50. Zhang, Z., \& He, L. W. (2004). Remote collaboration on physical whiteboards. In Advances in Multimedia Information Processing-PCM 2004 (pp. 105-113). Springer Berlin Heidelberg.

51. Zillner, J., Rhemann, C., Izadi, S., \& Haller, M. (2014, October). 3D-board: a whole-body remote collaborative whiteboard. In Proceedings of the 27th annual ACM symposium on User interface software and technology (pp. 471-479). ACM. 